\title{
THE FREE SULFHYDRYL GROUP (Cys341) OF CARBOXYPEPTIDASE Y: FUNCTIONAL EFFECTS OF MUTATIONAL SUBSTITUTIONS
}

\author{
by \\ JAKOB R. WINTHER and KLAUS BREDDAM \\ Department of Chemistry, Carlsberg Laboratory, \\ Gamle Carlsberg Vej 10, DK-2500 Copenhagen Valby
}

\begin{abstract}
Keywords: Carboxypeptidase Y, site-directed mutagenesis, serine protease, cysteinyl residue, catalytic mechanism
\end{abstract}

Carboxypeptidase $Y$ from yeast contains a free sulfhydryl group (Cys341) which is important to the catalytic efficiency and the stability of the enzyme. A number of mutant enzymes have been constructed using a semi-random oligonucleotide directed mutagenesis method. Mutant enzymes, in which Cys 341 had been replaced by Ser, Gly, Gln, and Glu, were subjected to kinetic analysis and found to have greatly reduced activities towards a wide range of dipeptide and ester substrates. However, for the Glu34l substituted enzyme the activity towards Bz-Lys-OMe was 4 fold higher than that of the wild type enzyme. The thermal stability as well as $\mathrm{pH}$ stabilities of these mutated enzymes were significantly reduced as compared with wild type carboxypeptidase $Y$, and the enzymes containing His and Lys at position 341 were inactive. The possible functional relation between Cys341 of carboxypeptidase $\mathrm{Y}$ and the free cysteinyl group (Cys72) of proteinase $\mathrm{K}$ from Tritirachium album Limber is discussed.

\section{INTRODUCTION}

A number of serine endopeptidases related to the subtilisins are inhibited by mercurials due to the modification of a single cysteinyl residue. The three-dimensional structure of proteinase $\mathrm{K}$ from Tritirachium album Limber suggests that the cysteinyl residue is situated in the vicinity of the essential histidyl residue of the enzyme (2).
Some serine carboxypeptidases also contain such a cysteinyl residue, and since they are genetically unrelated to the subtilisins it is probable that the cysteinyl residue has a common function to the two groups of enzymes, and could play a specific role in the catalytic mechanism or substrate binding. The cysteinyl residue of carboxypeptidase $\mathrm{Y}$ from yeast (CPD-Y) is

Abbreviations: Ches $=2$ (N-Cyclohexylamino)ethanesulfonic acid; $\mathrm{CPD}-\mathrm{Y}=$ carboxypeptidase $\mathrm{Y} ; \mathrm{CPD}-\mathrm{Y}-\mathrm{Hg}^{+}=$ CPD-Y modified with $\mathrm{Hg}^{++}$ions; EDTA = ethylenediamine tetraacetic acid; $\mathrm{FA}=$ furylacryloyl; Hepes = N-2-hydroxyethylpiperazine-N'-2-ethanesulfonic acid; Mes = 2-(N-morpholino) ethanesulfonic acid; $R F=$ replicative form; SDS $=$ sodium dodecyl sulfate; ssDNA $=$ single-stranded DNA; Tris $=$ tris(hydroxymethyl)aminomethane; Xaa-341-CPD-Y = CPD-Y with amino acids other than cysteine at position 341 (Xaa = Gly, Ser, Gln, Glu, His, Lys, Asp or Asn). The binding site notation is that of SCHECHTER and BerGer (18). Accordingly, the binding site of the C-terminal amino acid of the substrate is denoted $\mathrm{S}_{1}$ and those of the amino acid residues in the amino terminal direction away from the cleaved bond is denoted $S_{1}, S_{2}, \ldots, S_{n}$. In analogy to this the subtrate residues are denoted: $P_{1}^{\prime}$ and $P_{1}, P_{2}, \ldots, P_{n}$. 
not essential to catalysis since certain chemical modifications merely reduce activity $(3,4)$. In the present paper the role of this cysteinyl residue (Cys341) is further studied by replacing it with a number of other amino acid residues by means of site-directed mutagenesis. Some of these mutants were obtained by a modification of the method described by T. KUNKEL (11) by which multiple mutations efficiently can be introduced at codon 341 using a mixture of synthetic oligonucleotides. It is shown that the CPD-Y mutants with serine, glycine, glutamic acid and glutamine at position 341 are active whereas those with lysine and histidine are inactive.

\section{MATERIALS AND METHODS}

\subsection{Materials}

The plasmid pTSY3, containing the $P R C 1$ gene coding for CPD-Y, and the Saccharomyces

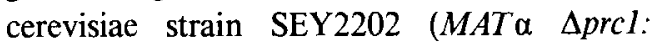
:(LEU2) leu2-3,112 ura3-52 his4-519) were kindly provided by Dr. TOM STEVENS, Institute of Molecular Biology, University of Oregon, USA. E. coli strain RZ1032 (11) was a generous gift from Dr. Thomas KUNKEL, National Institute of Environmental Health Sciences, Research Triangle Park, N.C., USA. Phage M13mp8 (15) and Escherichia coli JM101 (13) were from house collections.

Restriction endonucleases, T4 DNA ligase, DNA polymerase I (Klenow fragment), T4 polynucleotide kinase, 2'-deoxyribonucleotide triphosphates, adenosine triphosphate and the M13 sequencing primer 5'-d(TCCCAGTCACGACTG)-3' were obtained from Boehringer Mannheim, FRG. 2',3'-dideoxyribonucleotide triphosphates were obtained from P-L Biochemicals, USA. $\left[\alpha-{ }^{32}\right.$ P]dATP $(>800$ $\mathrm{Ci} / \mathrm{mmol})$ and $\left[\gamma_{-}{ }^{32} \mathrm{P}\right] \mathrm{ATP}(>7000 \mathrm{Ci} / \mathrm{mmol})$ were from New England Nuclear, USA. All reagents for synthesis of oligonucleotides were from Applied Biosystems. Nitrocellulose filters were from Schleicher \& Schuell, FRG. Trizma base, Mes, Hepes, Ches, DTT and agarose were from Sigma, USA. FA-Phe-OMe was purchased from Bachem, Switzerland and Bz-LysOMe tosylate was suplied from Carlsberg Bio- technology Ltd., Denmark. All other chemicals and solvents were of analytical grade.

The following compounds were synthesized as previously described (3): FA-Phe-Ala-OH, FA-Phe-Val-OH, FA-Phe-Leu-OH, FA-Phe-Phe$\mathrm{OH}$, FA-Ile-Phe-OH FA-Val-Phe-OH, FA-AlaPhe-OH, FA-Phe-OEt, FA-Ala-OBzl and FAArg-OMe. Synthetic media for the growth of yeast were prepared as described by PETERSEN et al. (16).

\subsection{Methods}

\subsubsection{In vitro mutagenesis of codon 341 in PRC1}

The construction of a recombinant M13 phage, G42, containing the $303 \mathrm{C}$-terminal base pairs of the $P R C 1$ coding region, subcloned from the YEp24 (6) derived plasmid, pTSY3 (20), has been described earlier (23), and a corresponding uracil containing derivative, $\mathrm{G} 42^{\mathrm{u}}$, was prepared as described by KUNKEL (11).

Synthetic oligonucleotides were synthesized on an Applied Biosystems 380A DNA synthesizer according to the procedures provided by the manufacturer. The oligonucleotides coding for serine (PR341Ser: 5'-d(TTCATCGGTAACTGG)-3') and glycine (PR341Gly: 5'd(TTCATCTCTAACTGG)-3') at position 341 covered codons 339-343. A mixture of oligonucleotides covering codons 338-344 coding for His, Gln, Asn, Lys, Asp or Glu at codon 341 (PR341X: 5'-d(GATTTCATCZAZAACTGGTTG)-3' where $Z$ indicates $C$, $A$ or $G$ ) was synthesized by adding a 1:1:1 mixture of $C, A$, and $G$ phosphoramidites at the $Z$-positions. When hybridized to the $G 42^{u}$ template the PR341Ser and PR341Gly 15'mer primers contained one mismatch each, while the PR341X 21 'mer contained three (Figure 1). The crude oligonucleotide preparations were desalted on a $1 \times 5 \mathrm{~cm}$ Sephadex G50 column equilibrated with distilled water. They were used without further purification. Phosphorylation of the oligonucleotides was carried out as described (24) and the resulting reaction mixtures were used directly in the mutagenesis reactions. Template ssDNA was prepared from $\mathrm{G} 42^{u}$ phage particles and in vitro mutagenesis was carried 
J.R. WINTHER \& K. BREDDAM: Cysteine 341 of carboxypeptidase $Y$

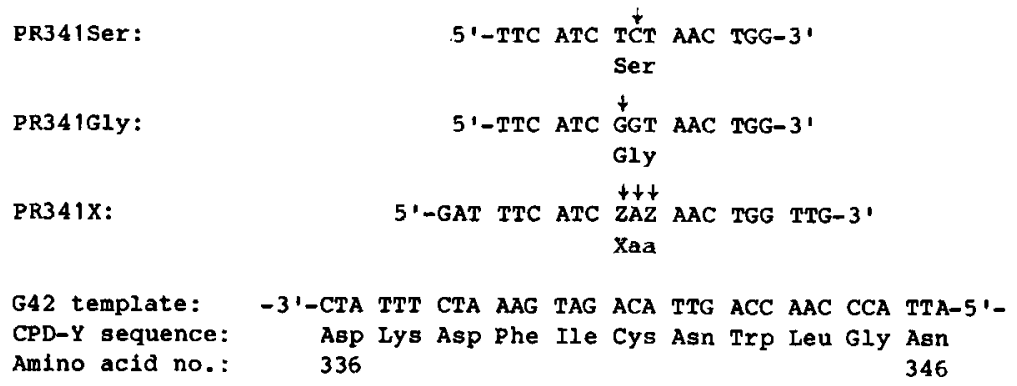

Figure 1. The sequence of mutagenic primers used in the present work. Positions of base mismatch are indicated with $\downarrow . Z$ indicales the bases $C, A$ or $G$ and $X a a$ indicates amino acid residues: histidine, glutamine, aspartate, glutamate, asparagine or lysine.

out using oligonucleotide-primed synthesis of a secondary strand as described (23). The Ser341 mutation was obtained using 0.1 pmol G42" template ssDNA and 4 pmol oligonucleotide PR341Ser, while the Gly341 mutation was introduced using 0.1 pmol G42 ${ }^{u}$ ssDNA and 8 pmol PR 341Gly. Semi-random mutagenesis of codon 341 was achieved by the use of 1 pmol G42 ${ }^{\mathrm{u}}$ and $24 \mathrm{pmol}$ of the PR341X mixture. Each reaction was carried out with 1-3 units of the large Klenow fragment of DNA polymerase I and 3 units of T4 DNA ligase. The three reaction mixtures were used without further purification for the transfection of $\mathrm{CaCl}_{2}$ treated JM 101 cells according to standard procedures (14).

Phage stocks were prepared by propagation of individual plaques and putative mutants were identified by hybridization of the appropriate ${ }^{32}$ P-labelled mutagenic oligonucleotides to phage ssDNA spotted onto nitrocellulose filter as described previously (23). Phage DNA preparations showing stronger hybridization signal than the $G 42$ control DNA were subjected to two successive rounds of plaque purification and resulting clones were sequenced (17) for confirmation of their mutant identity. Mutated derivatives of the BglII-PvuII fragment were reintroduced into the original $P R C l$ gene context in pTSY3 as described (23), yielding plasmids that carry the complete, mutated $P R C 1$ genes, can replicate in yeast and can be selected in yeast by means of the URA3 gene. S. cerevisiae strain SEY2202 was transformed (8) to uracil independence with these plasmids. Transformants were kept on synthetic complete medium without uracil to maintain selection for the presence of plasmid. Cells were grown to saturation for preparation of enzyme.

\subsubsection{Purification and characterization of mutant enzymes}

Mutant CPD-Y's were purified by affinity chromatography as described for wild type CPD-Y (10) and the purification of Ser341CPD-Y and Gly341-CPD-Y was followed by assay of the activity towards $0.3 \mathrm{~mm}$ FA-PheLeu-OH in 50 mM-Mes, 1 mM-EDTA, pH 6.5, while Glu341-CPD-Y and Gln341-CPD-Y was assayed towards $0.2 \mathrm{~mm}$ FA-Ala-OBzl in 50 mM-Hepes, 1 mM-EDTA, $2.5 \%(\mathrm{v} / \mathrm{v})$ methanol, $\mathrm{pH}$ 7.5. The purity of the resulting enzymes were ascertained by SDS-polyacrylamide gel electrophoresis on $1 \mathrm{~mm}$ thick $7.5 \%$ gel slabs in a continuous SDS-phosphate buffer system (21). The enzyme was identified as a CPD-Y derivative by amino acid sequencing of the $\mathrm{N}$-terminal section using a Beckman $890 \mathrm{C}$ liquid phase sequencer. Reactivity of the mutant enzymes towards mercuric ions was tested in the following way: $0.5 \mathrm{nmol}$ enzyme was incubated with 1 $\mathrm{nmol} \mathrm{HgCl}_{2}$ in $100 \mu$ l of $50 \mathrm{~mm}$-Hepes buffer, $\mathrm{pH}$ 7.5 at $22{ }^{\circ} \mathrm{C}$ and aliqouts were assayed as a function of time for activity towards $0.2 \mathrm{~mm}$ FA-Ala-OBzl in $50 \mathrm{~mm}$-Hepes, $2.5 \%$ methanol (v/v), $\mathrm{pH} 7.5$. 


\subsubsection{Determination of kinetic constants and stability}

The kinetic constants for the hydrolysis of various FA-peptide and ester substrates were determined from Lineweaver-Burk plots. Hydrolysis rates at $25^{\circ} \mathrm{C}$ were determined spectrophotometrically at selected wavelengths in the range 329-358 $\mathrm{nm}$, depending on substrate concentration. Peptide substrates were assayed in $50 \mathrm{~mm}$-Mes, $1 \mathrm{~mm}$-EDTA, pH 6.5 whereas ester substrates were assayed in $50 \mathrm{mM}$-Hepes, 1 mM-EDTA, $2.5 \%(v / v)$ methanol, pH 7.5. Determinations of $\mathrm{k}_{\mathrm{cat}}$ and $\mathrm{K}_{\mathrm{m}}$ for the hydrolysis of FA-Phe-Phe-OH, FA-Ile-Phe-OH and FA-ValPhe-OH were performed at $\mathrm{pH} 7.2$ in $50 \mathrm{~mm}$ Hepes, 1 mm-EDTA, pH 7.2 due to unmeasurably low $\mathrm{K}_{\mathrm{m}}$ values at $\mathrm{pH} 6.5$. Hydrolysis of Bz-Lys-OMe was followed spectrophotometrically at $260 \mathrm{~nm}$ in $50 \mathrm{~mm}$-Hepes, $1 \mathrm{~mm}$-EDTA, $\mathrm{pH}$ 7.5. The high $\mathrm{K}_{\mathrm{m}}$ value precluded determination of $k_{\text {cat }}$ and $K_{m}$ for this substrate; $k_{\text {cat }} / K_{m}$ values were, however, obtained from the slope of Lineweaver-Burk plots.

The stabilities of the enzymes were measured in $50 \mathrm{~mm}$-Mes, $1 \mathrm{~mm}$-EDTA, pH 6.5 at $50{ }^{\circ} \mathrm{C}$ and in $50 \mathrm{~mm}$-Ches, $1 \mathrm{~mm}$-EDTA, pH 9.0 at 25 ${ }^{\circ} \mathrm{C}$, respectively. Activities were measured as a function of time by assaying CPD-Y, Ser341and Gly34l-CPD-Y against $0.3 \mathrm{~mm}$ FA-PheLeu-OH in 50 mM-Mes, 1 mM-EDTA, pH 6.5 and Glu341- and Gln341-CPD-Y against 0.2 mM FA-Ala-OBzl in $50 \mathrm{~mm}$-Hepes, $1 \mathrm{~mm}$-EDTA, $2.5 \%(\mathrm{v} / \mathrm{v})$ methanol, $\mathrm{pH} 7.5$.

\section{RESULTS}

\subsection{Site-directed mutagenesis}

To increase the oligonucleotide directed mutation frequency, as compared to conventional procedures (24), the method of T. KUNKEL (11) was employed: the $G 42$ phage (see section 2.2.1) was converted into the corresponding uracilcontaining phage, $\mathrm{G} 42^{\mathrm{u}}$, by infection of an $\mathrm{E}$. coli strain, RZ1032 (11), deficient in dUTP'ase $\left(d u t^{-}\right)$and uracil-N-glycosylase $\left(u n g^{-}\right)$. DNA from the produced phage particles was used as template for in vitro primed secondary strand synthesis using mutagenic oligonucleotides. E. coli cells which are wild type with respect to the

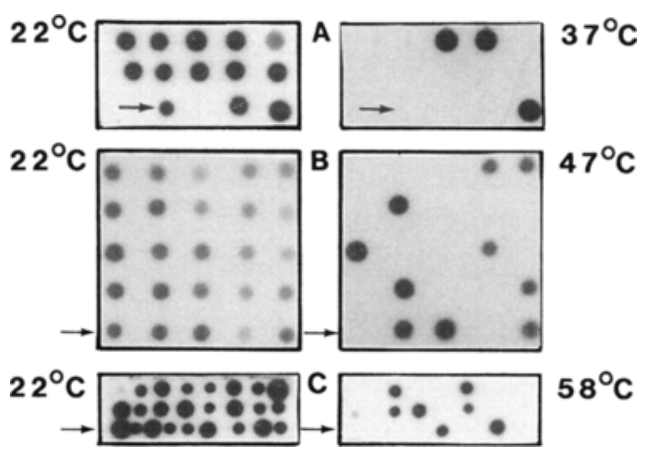

Figure 2. Dot-blot hybridization screening for coding 341 mutants using ${ }^{32} \mathrm{P}$-labelled mutagenic oligonucleotide probes. The relevant probes were initially hybridized to ssDNA's prepared from individual mutagenesis experiments at $22{ }^{\circ} \mathrm{C}$ (left). Stringent temperatures (right) were determined empirically by perform. ing several rounds of wash in $0.9 \mathrm{M}-\mathrm{NaCl}, 0.09 \mathrm{M}$-sodium citrate followed by autoradiography as described in reference 23 . It was found that 3 out of 12 hybridized with the PR341Ser oligonucleotide probe at $37^{\circ} \mathrm{C}(\mathrm{A})$, while 10 out of 24 hybridized with the PR 341 Gly probe at $47{ }^{\circ} \mathrm{C}$ (B) and 7 out of 24 hybridized with the PR $341 \mathrm{X}$ probe at $58{ }^{\circ} \mathrm{C}(\mathrm{C})$. At these temperatures none of the probes hybridized to the control G42 ssDNA $(\rightarrow)$.

ung gene should not support the growth of resulting phage particles, since uracil residues and subsequently apyrimidinic sites are removed leaving lethal gaps in the phage genome. The plating efficiency of G42 ${ }^{\mathrm{u}}$ on RZ1032 (dut', ung $g^{-}$was $10^{6}$ times that on JM101 (dut $\left.t^{+}, u n g^{+}\right)$, consistent with previous results (11).

Transfection of JM101 with the complete mutagenesis mixtures (containing $0.1 \mathrm{pmol}$ template) yielded between 25 and 50 plaques, reflecting a very low infectivity of the in vitro synthezised DNA. The low infectivity of the in vitro synthezised double-stranded DNA could be due to impurities (e.g. dUTP) in the nucleotide triphosphates used for the secondary strand synthesis, since later experiments have yielded $10-100$ fold higher transfection frequencies using the same template and procedure but employing HPLC purified nucleotide triphosphates from Pharmacia P-L Biochemicals.

Potential mutant clones were selected (see 
J.R. WINTHER \& K. BREDDAM: Cysteine 341 of carboxypeptidase Y

Table I. Kinetic parameters towards peptide substrates.

\begin{tabular}{|c|c|c|c|c|c|}
\hline Substrate & Enzyme & $\begin{array}{c}k_{\text {cat }} \\
\left(\mathrm{min}^{-1}\right)\end{array}$ & $\begin{array}{c}\mathrm{K}_{\mathrm{m}} \\
(\mathrm{mM})\end{array}$ & $\begin{array}{c}\mathbf{k}_{\mathrm{cal}} / \mathrm{K}_{\mathrm{m}} \\
\left(\mathrm{min}^{-1} \cdot \mathrm{mM}^{-1}\right) \\
\end{array}$ & $\begin{array}{l}\text { Relative } \\
\mathrm{k}_{\mathrm{cat}} / \mathrm{K}_{\mathrm{m}}\end{array}$ \\
\hline \multirow[t]{5}{*}{ FA-Phe-Ala-OH } & CPD-Y & 9700 & 0.14 & 61000 & 1 \\
\hline & Gly341-CPD-Y & 450 & 0.21 & 2100 & 1 \\
\hline & Ser341- CPD-Y & 1700 & 1.0 & 1700 & 1 \\
\hline & Glu341-CPD-Y & 750 & 6 & 130 & 1 \\
\hline & Gln341-CPD-Y & 170 & 3.7 & 46 & 1 \\
\hline \multirow[t]{5}{*}{ FA-Phe-Val-OH } & CPD-Y & 6500 & 0.047 & 140000 & 2.3 \\
\hline & Gly341-CPD-Y & 530 & 0.038 & 14000 & 6.7 \\
\hline & Ser341-CPD-Y & 1400 & 0.08 & 16000 & 9.4 \\
\hline & Glu341-CPD-Y & 670 & 0.54 & 1300 & 10.0 \\
\hline & $\mathrm{Gln} 341-\mathrm{CPD}-\mathrm{Y}$ & 110 & 0.45 & 250 & 5.4 \\
\hline \multirow[t]{5}{*}{ FA-Phe-Phe-OH ${ }^{b}$} & CPD-Y & 6300 & 0.11 & 53000 & 0.87 \\
\hline & Gly341-CPD-Y & 370 & 0.065 & 5700 & 2.7 \\
\hline & Ser341- CPD-Y & 800 & 0.13 & 6000 & 3.5 \\
\hline & Glu341-CPD-Y & 160 & 0.44 & 400 & 3.1 \\
\hline & Gln341-CPD-Y & 35 & 0.38 & 110 & 2.4 \\
\hline \multirow[t]{5}{*}{ FA-Ile-Phe-OH ${ }^{b}$} & CPD-Y & 450 & 0.014 & 32000 & 0.52 \\
\hline & Gly341-CPD-Y & 170 & 0.075 & 2300 & 1.1 \\
\hline & Ser341- CPD-Y & 380 & 0.088 & 4300 & $2: 5$ \\
\hline & Glu341-CPD-Y & 170 & 0.18 & 920 & 7.1 \\
\hline & Gln341-CPD-Y & 90 & 0.76 & 110 & 2.4 \\
\hline \multirow[t]{5}{*}{ FA-Val-Phe-OH } & CPD-Y & 960 & 0.065 & 15000 & 0.26 \\
\hline & Gly341-CPD-Y & 270 & 0.19 & 1500 & 0.71 \\
\hline & Ser341- CPD-Y & 510 & 0.27 & 1900 & 1.1 \\
\hline & Glu341-CPD-Y & 120 & 0.20 & 570 & 4.4 \\
\hline & Gln341-CPD-Y & 80 & 0.9 & 95 & 2.1 \\
\hline \multirow[t]{5}{*}{ FA-Ala-Phe-OH ${ }^{a}$} & CPD-Y & 16000 & 1.20 & 13000 & 0.21 \\
\hline & Gly341-CPD-Y & 4600 & 0.91 & 5100 & 2.4 \\
\hline & Ser341-CPD-Y & 11000 & 4.0 & 2900 & 1.7 \\
\hline & Glu341-CPD-Y & 5600 & 5 & 1100 & 8.5 \\
\hline & Gln341-CPD-Y & 1000 & 6 & 170 & 3.7 \\
\hline
\end{tabular}

$P_{2} \quad P_{1} \quad P_{1}^{\prime}$

Determinations were performed as described in section 2.2 .4 where substrates marked ${ }^{\mathrm{a}}$ and ${ }^{\mathrm{b}}$ were determined at pH 6.5 and $\mathrm{pH} 7.2$, respectively.

Figure 2) and chain termination sequencing of one of each identified the Ser341 and Gly341 mutations obtained with non-degenerate oligonucleotides. The seven clones from the semi-random mutagenesis which showed elevated signals in the hybridization test were all sequenced, and the following codons at position 341 were identified: $1 \times$ GAA (Glu), $1 \times$ CAC
(His), $2 \times$ CAA (Gln) and $3 \times$ AAA (Lys). In order to obtain the complete mutated $P R C 1$ genes on a convenient yeast vector, RF-DNA was prepared from G42-derived clones representing each of the different mutations and the mutated $P R C I$ sequences were reintroduced into the pTSY3 plasmid replacing the original wild type sequence. 
J.R. WINTHER \& K. BREDDAM: Cysteine 341 of carboxypeptidase $Y$

Table II. Kinetic parameters towards ester substrates.

\begin{tabular}{|c|c|c|c|c|c|}
\hline Substrate & Enzyme & $\underset{\left(\min ^{-1}\right)}{\mathbf{k}_{\mathrm{rat}}}$ & $\begin{array}{c}\mathrm{K}_{\mathrm{m}} \\
(\mathrm{mM})\end{array}$ & $\begin{array}{c}\mathbf{k}_{\mathrm{cat}} / \mathrm{K}_{\mathrm{m}} \\
\left(\mathrm{min}^{-1} \cdot \mathrm{mM}^{-\mathrm{I}}\right)\end{array}$ & $\begin{array}{l}\text { Relative } \\
\mathrm{k}_{\text {cal }} / \mathrm{K}_{\mathrm{m}}\end{array}$ \\
\hline \multirow[t]{5}{*}{ FA-Phe-OMe } & CPD-Y & 11000 & 0.39 & 28000 & 1 \\
\hline & Gly341-CPD-Y & 5400 & 1.1 & 4900 & 1 \\
\hline & Ser341-CPD-Y & 21000 & 3 & 7300 & 1 \\
\hline & Glu341-CPD-Y & 220 & 2.5 & 86 & 1 \\
\hline & Gln341-CPD-Y & 180 & 6 & 29 & 1 \\
\hline \multirow[t]{5}{*}{ FA-Phe-OEt } & CPD-Y & 11000 & 0.059 & 190000 & 6.8 \\
\hline & Gly34 I-CPD-Y & 11000 & 0.26 & 44000 & 9.0 \\
\hline & Ser341-CPD-Y & 32000 & 0.5 & 63000 & 8.6 \\
\hline & Glu341-CPD-Y & 330 & 0.43 & 760 & 8.8 \\
\hline & Gln341-CPD-Y & 81 & 0.35 & 230 & 7.9 \\
\hline \multirow[t]{5}{*}{ FA-Ala-OBzl } & CPD-Y & 9100 & 0.054 & 170000 & 6.1 \\
\hline & Gly341-CPD-Y & 14000 & 0.17 & 78000 & 16 \\
\hline & Ser341-CPD-Y & 17000 & 0.38 & 43000 & 5.9 \\
\hline & Glu341-CPD-Y & 3500 & 1.0 & 3500 & 41 \\
\hline & Gln341-CPD-Y & $>3000$ & $>3$ & 790 & 27 \\
\hline \multirow[t]{5}{*}{ Bz-Lys-OMe } & CPD-Y & & & 1.6 & $6 \cdot 10^{-5}$ \\
\hline & Gly341-CPD-Y & & & 3 & $6 \cdot 10^{-4}$ \\
\hline & Ser341-CPD-Y & & & $<1$ & $<2 \cdot 10^{-4}$ \\
\hline & Glu341-CPD-Y & & & 6 & $7 \cdot 10^{-2}$ \\
\hline & Gln341-CPD-Y & & & 0.3 & $1 \cdot 10^{-2}$ \\
\hline
\end{tabular}

$\mathrm{P}_{2}-\mathrm{P}_{1}-\mathrm{P}_{1}^{\prime}$

Determinations of $k_{\text {cat }}$ and $K_{m}$ were performed as described in section 2.2.4.

\subsection{Characterization of the mutant enzymes}

S. cerevisiae strain SEY2202, which is deficient in endogenous CPD-Y synthesis, was transformed with plasmids containing the genes for Ser341-, Gly341-, Glu341-, Gln341-, His341- and Lys341-CPD-Y. Plasmid bearing yeast cells were grown to saturation on synthetic complete media and activity was found in the crude extracts of all transformants except those containing the genes for His341- and Lys341CPD-Y. These extracts were inactive towards FA-Phe-OMe, FA-Ala-OBzl, FA-Phe-Leu-OH and FA-Arg-OMe, and were consequently not purified. From $130 \mathrm{~g}$ of cells, wet weight, of each of the mutant strains, Ser341-, Gly341-, Glu341- and GIn341-CPD-Y were purified by affinity chromatography with recoveries of $30-$ $60 \%$ activity. Enzyme preparations of mutant enzymes were homogeneous as judged by SDS- polyacrylamide gel electrophoresis and the $\mathrm{N}$ terminal sequences were identical to that of wild type CPD-Y.

The activities of the purified mutant enzymes were not affected by 2 equivalents of $\mathrm{Hg}^{++}$as described in section 2.2.2. Under the same conditions CPD-Y was completely inactivated within $15 \mathrm{~min}$.

Substitution of the cysteinyl residue at position 341 in CPD-Y with any of the amino acid residues glycyl, seryl, glutamyl or glutaminyl resulted in a reduction in $\mathrm{k}_{\text {cat }} / \mathrm{K}_{\mathrm{m}}$ for the hydrolysis of all the substrates listed in Tables I and II, except Bz-Lys-OMe. With Gly341 and Ser341$C P D-Y$ the $k_{c a} / K_{m}$ values are similar and range from 3 to $50 \%$ of those with CPD-Y, dependent on the substrate. However, the values of $\mathbf{k}_{\text {cat }}$ and $\mathrm{K}_{\mathrm{m}}$ are consistently higher with Ser341-CPD-Y than with Gly341-CPD-Y. The $\mathrm{k}_{\mathrm{cal}} / \mathrm{K}_{\mathrm{m}}$-values 
Table III. Activity half-lives of CPD-Y and position 341 mutants of CPD-Y.

\begin{tabular}{lrc}
\hline Enzyme & $\mathrm{T}_{1 / 2}$ at $50{ }^{\circ} \mathrm{C}, \mathrm{pH} 6.5$ & $\mathrm{~T}_{1 / 2}$ at $25^{\circ} \mathrm{C}, \mathrm{pH} 9.0$ \\
\hline CPD-Y & $148 \mathrm{~min}$ & $>300 \mathrm{~min}$ \\
Gly341-CPD-Y & $36 \mathrm{~min}$ & $68 \mathrm{~min}$ \\
Ser341-CPD-Y & $15 \mathrm{~min}$ & $25 \mathrm{~min}$ \\
Glu341-CPD-Y & $9 \mathrm{~min}$ & $14 \mathrm{~min}$ \\
Gln341-CPD-Y & $9 \mathrm{~min}$ & $62 \mathrm{~min}$ \\
\hline
\end{tabular}

Determinations were carried out as described in section 2.2.4.

with Glu341-CPD-Y are all lower than those with Gly341- and Ser341-CPD-Y and less than $10 \%$ of the wild type values. The Gln 341 mutant is characterized by even further reduced $\mathrm{k}_{\text {cat }} / \mathrm{K}_{\mathrm{m}}{ }^{-}$ values, all being less than $2 \%$ of the wild type values.

The $\mathrm{k}_{\mathrm{cat}}$-values of Gly341- and Ser341-CPD$Y$ towards the hydrophobic ester substrates are remarkable because they are much higher than those towards peptide substrates and in most cases even exceed those of CPD-Y. In contrast, the $\mathrm{k}_{\mathrm{cat}}$-values of Glu341- and Gln341-CPD-Y are reduced approximately to the same extent for peptide and ester substrates.

Bz-Lys-OMe constitutes a special case since Glu341- and Gln341-CPD-Y exhibit greatly increased preference towards this substrate, when compared with both CPD-Y and the Gly341 and Ser341 mutants. Hence, Bz-LysOMe represents the only substrate which is hydrolysed with a higher rate by a mutant enzyme as compared with the wild type enzyme. The resulting specificity change is illustrated by the $k_{\text {cal }} / K_{m}$ ratio of FA-Phe-OMe to Bz-Lys-OMe which is more than $10^{3}$ for CPD-Y, Gly341CPD-Y and Ser341-CPD-Y, while only 10 for Glu341-CPD-Y and $10^{2}$ for Gln341-CPD-Y.

The introduction of the ionizable group of glutamic acid at position 341 does not affect the $\mathrm{pH}$ profile of the kinetic parameters for the hydrolysis of FA-Phe-OEt as determined at $\mathrm{pH}$ 5.0, 7.5 and 9.0 and an increased ionic strength of the assay medium had the same influence on the activity of Glu341- and Gln341-CPD-Y (data not shown).

The inactivation rates of CPD-Y and the mutant enzymes at $50^{\circ} \mathrm{C}, \mathrm{pH} 6.5$ and at $25^{\circ} \mathrm{C}$,
pH 9.0 are indicated in Table III. Activity decays obeyed first order kinetics and all mutants showed decreased stabilities compared to wild type enzyme; notably, the stability at $\mathrm{pH} 6.5$ was the same for Glu341- and Gln341-CPD-Y, while the stability at $\mathrm{pH} 9.0$ was significantly reduced for Glu341-CPD-Y compared to Gln341-CPD-Y.

\section{DISCUSSION}

\subsection{Oligonucleotide directed semi-random mutagenesis}

Semi-random mutagenesis by the simultaneous use of several synthetic oligonucleotides may be the preferred method in cases where the effects of of the mutations cannot be predicted $(7,19,22)$. In the present case alteration of the Cys341 codon of CPD-Y, TGT, to a number of different hydrophilic amino acid codons could be achieved by changing this codon to $\mathrm{ZAZ}$, where $Z$ was either $C$, $A$ or $G$, thus coding for histidine, glutamine, aspartate, glutamate, asparagine or lysine. Synthetic oligonucleotides were prepared by an automated procedure and a mixture with a composition corresponding to the desired sequences could easily be obtained by addition of a solution of the apropriate base-derivatives at the Z-positions. Thymidinderivatives were omitted from the solution (Figure 1) to avoid undesired hybridization of some oligonucleotides as a consequence of A-T basepairing. This would otherwise cause high frequencies of mutation to certain codons. The mutagenesis experiment employing this oligonucleotide mixture as priming agent on a 
uracil-containing template and the subsequent screening and sequencing of phage progeny showed that: 1) mutations could be identified by dot-blot hybridization; 2) mutants appeared at a frequency of roughly $30 \% ; 3$ ) a reasonable distribution of codons was found among those anticipated and 4) no mutations were found among the approximately 300 base pairs outside the intended site.

The described method for introduction of semi-random mutations offers some advantages compared to the cassette method (22), since it is easier and more reliable with respect to confining mutations to the intended site (22). It should be noted that erroneous biproducts in the synthetic oligonucleotide preparation probably do not form stable duplexes with the template due to additional base mismatches and/or reduced length.

\subsection{The role of Cys341}

The endopeptidases thermitase from Thermoactinomyces vulgaris $(1,12)$, proteinase $\mathrm{K}$ from Tritirachium album (9) and proteinase B from yeast (E.W. JONES, personal commun.) belong to a group of subtilisin-like enzymes that contain free cysteine residues. The three-dimensional structure of proteinase $\mathrm{K}$ shows that the free cysteinyl residue of this enzyme (Cys72) is buried underneath the essential histidyl of the catalytic triad (Ser, His, Asp) (2). It has been suggested (2) that this sulfhydryl group could participate in catalysis or could have a structural function. It is possible that Cys 72 of proteinase $\mathrm{K}$ functionally resembles the free cysteinyl residue (Cys 341) of the serine carboxypeptidase from yeast (CPD-Y) since both enzymes are inhibited by mercurials. When the single sulfhydryl group of CPD-Y is modified with alkyl-mercurials the activity is reduced, but not completely abolished, suggesting that the cysteinyl residue is not essential for catalysis $(3,4$, 5). However, its modification alters the specificity with respect to the $P_{1}$ position of all types of substrates, suggesting that Cys 341 is situated in or close to the $S_{1}$ binding site of CPD-Y.

The chemical modification of CPD-Y with mercuric ions is a highly specific reaction which results in formation of an inactive CPD-Y- $\mathrm{Hg}^{+}$ derivative $(4,5)$. The fact that $\mathrm{Hg}^{++}$-ions did not inactivate any of the mutants presented in this work confirms the notion that the cysteinyl residue at position 341 is the site of action of mercuric ions in the wild type enzyme.

The influence of the mutations at position 341 on enzyme specificity is apparent from the relative $k_{c a t} / K_{m}$ values for the hydrolysis of peptide substrates, calculated with FA-Phe-Ala$\mathrm{OH}$ serving as a reference for each enzyme (Table I). The values for each substrate, as obtained with the five enzymes, differ significantly, in particular for FA-Ala-Phe-OH. This alteration in the substrate preference is further illustrated by normalizing the values for each substrate to those of wild type CPD-Y (Figure 3). All the mutant enzymes, i.e. Gly341-, Ser341-, Glu341- and Gln341-CPD-Y, exhibit normalized values around 3 for the hydrolysis of both FA-Phe-Val-OH and FA-Phe-Phe-OH. However, when the amino acid residue at the $P_{1}$ position is reduced in size, i.e. FA-Ile-Phe-OH, FA-Val$\mathrm{Phe}-\mathrm{OH}$ and FA-Ala-Phe-OH, the normalized values for Gln341-CPD-Y and in particular Glu341-CPD-Y are increased much more. It is thus apparent that the nature of the amino acid occupying position 341 only has a slight influence on the preference with respect to the $P_{i}$ position but a significant influence on that with respect to the $P_{1}$ position. A simple interpretation is that a smaller size of the $P_{1}$ residue compensates for a larger size of a residue in the $S_{1}$ site.

The high $\mathrm{k}_{\text {cat }}$ values of Gly341- and Ser341CPD-Y towards FA-Phe-OEt and FA-Ala-OBzl are conspicuous but seem to be confined to CPD-Y-derivatives with only moderate changes at position 341 since neither Glu341-CPD-Y, Gln341-CPD-Y nor the chemically modified derivatives $(3,5)$ show this characteristic. The relative $\mathrm{k}_{\text {cat }} / \mathrm{K}_{\mathrm{m}}$ values for the hydrolysis of Bz-Lys-OMe, with FA-Phe-OMe serving as a reference (see Table II), vary drastically. The normalized value increases from 10 to $10^{3}$ through the series: Gly341-, Ser341-, Gln341and Glu341-CPD-Y, suggesting that an increased allowance for Lys in the $P_{1}$ position requires that the alteration at position 341 is drastic. A similar specificity change was ob- 


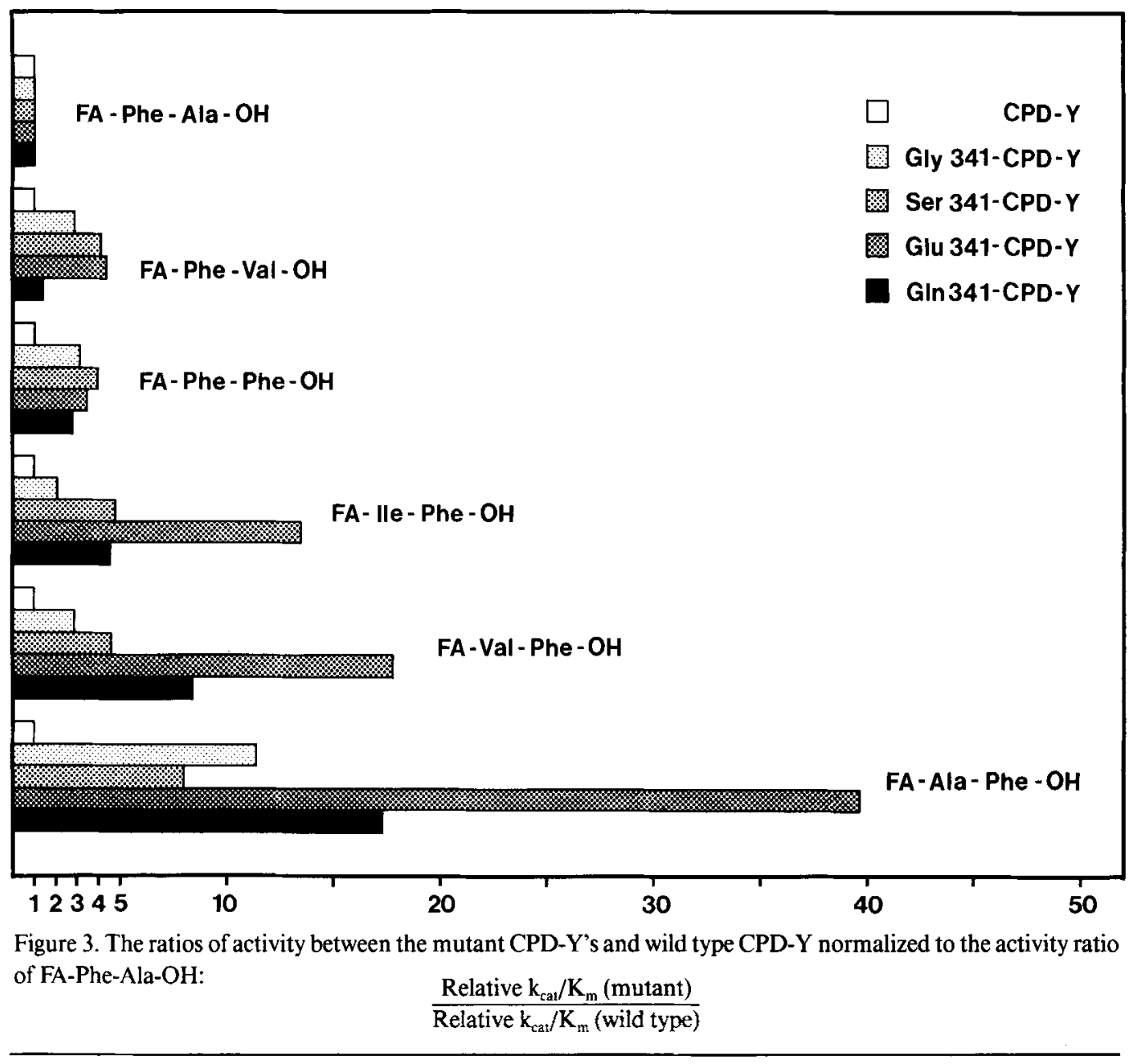

served by modification of CPD-Y with $\mathrm{HgI}^{+}$(5), i.e. the side-chain at position 341 was $-\mathrm{CH}_{2}$-S$\mathrm{Hg}-\mathrm{I}$, whereas cyanylation of the $-\mathrm{SH}$ group to produce $-\mathrm{CH}_{2}-\mathrm{S}-\mathrm{CN}$ had much less effect (unpublished results). The specificity change in direction of a higher tolerance of Bz-Lys-OMe, may result from electrostatic interactions or from opening of the active site due to conformational changes induced in the enzyme structure.

The $\mathrm{k}_{\mathrm{ca}} / \mathrm{K}_{\mathrm{m}}$ values of Gly341-CPD-Y and Ser341-CPD-Y are similar but Ser341-CPD-Y exhibits higher $\mathrm{k}_{\mathrm{cat}}$ and $\mathrm{K}_{\mathrm{m}}$ values than Gly341CPD-Y which might reflect a higher degree of functional resemblance between the seryl and the cysteinyl residues, both being hydrogen bond donors. It is probable that Cys 341 is buried in a hydrophobic environment away from the enzyme surface, since it is inaccessable to alkylating reagents and Ellman's reagent. The higher $\mathrm{K}_{\mathrm{m}}$ thus might reflect a distortion of the tertiary structure due to coordination of water molecules around the hydrophilic seryl sidechain. The significantly lower stability of the Ser341 enzyme compared to the wild type enzyme and Gly341-CPD-Y at $50^{\circ} \mathrm{C}, \mathrm{pH} 6.5$ and $25{ }^{\circ} \mathrm{C}$, pH 9.0 supports this assumption. A stabilizing function of the cysteinyl residue has also been proposed for the thermostable proteases proteinase $K$ and thermitase (2).

The present work confirms that although the free sulfhydryl group of CPD-Y is not essential to catalysis, it exerts a function which is very 
sensitive to modifications. Even the moderate change to a hydroxyl group results in marked reductions in catalytic efficiency and thermal stability and the introduction of more radical changes drastically alters specificity (as with the Glu341, Gln341 derivatives) or completely depletes activity (as with the His 341 , Lys 341 or $\mathrm{Hg}^{++}$-derivatives).

\section{ACKNOWLEDGEMENTS}

Professors MARtin OtTESEn and MoRTen KIELLAND-BRANDT are thanked for their interest and encouragement during this work and for critically revising the manuscript. Dr. ToM STEVENS, Institute of Molecular Biology, University of Oregon, USA, is acknowledged for his donation of the pTSY 3 plasmid, the S. cerevisiae strain SEY2202 and for providing the complete DNA-sequence of $P R C 1$ prior to its publication. Dr. ThOMAS A. KunKEL, National Institute of Environmental Health Sciences, USA, is thanked for providing the E. coli strain RZ1032. Dr. ElIZABETH A. JACKSON is acknowledged for preparing synthetic oligonucleotides.

\section{REFERENCES}

1. Baudyš, M., V. Kostka, G. Hausdorf, S. Fittkau \& W. E. HÖHNE: Amino acid sequence of the tryptic SH-peptide of thermitase, a thermostable serine proteinase from Thermoactinomyces vulgaris. Relation to the subtilisins. Int. J. Peptide Protein Res. 22, 66-72 (1983)

2. Betzel, C., G. P. Pal, M. Struck, K. -D. Jany \& W. SAENGER: Active-site geometry of proteinase $\mathrm{K}$. Crystallographic study of its complex with a dipeptide chloromethyl ketone inhibitor. FEBS Lett. 197, 105-110 (1986)

3. Breddam, K. \& A. Kanstrup: Cyanylation of the single sulfhydryl group in carboxypeptidase $\mathrm{Y}$ with cyanogen bromide. Carlsberg Res. Commun. 52, 65-71(1987)

4. BREdDAM. K. \& I. SvendSEN: Identification of methionyl and cysteinyl residues in the substrate binding site of carboxypeptidase Y. Carlsberg Res. Commun. 49, 639-645 (1984)

5. BREDDAM, K: Modification of the single sulfhydryl group of carboxypeptidase $\mathrm{Y}$ with mercurials.
Influence on enzyme specificity. Carlsberg Res. Commun. 48, 9-19 (1983)

6. Botstein, D., S. C. Falco. S. E. Stewart, M. BrenNAN, S. SCHERER, D. T. STinCHCOMB, K. STRUHL \& R. W. DAVIS: Sterile host yeasts (SHY): A eukaryotic system of biological containment for recombinant DNA experiments. Gene 8, 17-24 (1979)

7. Hirose, S., K. Takeuchi, H. Hori, T. Hirose, S INAYAMA \& Y. SUzuKI: Contact points between transcription machinery and the fibroin gene promoter deduced by functional tests of single-base substitution mutants. Proc. Natl. Acad. Sci. USA 81, 1394-1397 (1984)

8. Ito, H., Y. Fukuda. K. Murata \& A. Kimura: Transformation of intact yeast cells treated with alkali cations. J. Bacteriol. 153, 163-168 (1983)

9. JANY, K. -D., G. LEDERER \& B. MAYER: Amino acid sequence of proteinase $\mathrm{K}$ from the mold Tritirachium album Limber. Proteinase $\mathrm{K}$ - a subtilisin-related enzyme with disulfide bonds. FEBS Lett. 199, 139-144 (1986)

10. Johansen. J. T., K. Breddam \& M. OtTeSEn: Isolation of carboxypeptidase $Y$ by affinity chromatography. Carlsberg Res. Commun. 41, 1-14 (1976)

11. KUNKel, T. A.: Rapid and efficient site-specific mutagenesis without phenotypic selection. Proc. Natl. Acad. Sci. USA 82, 488-492 (1985)

12. Meloun, B., M. Baudyś, V. Kostka, G. Hausdorf, C. FRÖMMEL \& W. E. HÖHNE: Complete primary structure of thermitase from Thermoactinomyces vulgaris and its structural features related to the subtilisin-type proteinases. FEBS Lett. 183, 195200 (1985)

13. Messing, J:: A multi-purpose cloning system based on the single-stranded DNA bacteriophage M13. Recombinant DNA Tech. Bull., NIH publication No. 79-99, 2, 43-48 (1979)

14. Messing, J.: New M13-vectors for cloning. Methods Enzymol. 101, 20-78 (1983)

15. Messing J.\& J. Vieira: A new pair of M13 vectors for selecting either DNA strand of double-digest restriction fragments. Gene 19, 269-276 (1982)

16. Petersen, J. G. L.. M. C. Kielland-Brandt. S. Holmberg \& T. Nilsson-Tillgren: Mutational analysis of the isoleucine-valine biosynthesis in Saccharomyces cerevisiae. Mapping of ilv2 and ilv5. Carlsberg Res. Commun. 48, 21-43 (1983)

17. SANGer. F., S. Nicklen \& A. R. COUlson: DNA sequencing with chain-terminating inhibitors. Proc. Natl. Acad. Sci. USA 74, 5463-5467 (1977)

18. SCHECHTER, I.\& A BERGER: On the size of the active site of proteases. I. Papain. Biochem. Biophys. Res. Commun. 27, 157-167 (1967)

19. Seeburg, P. H.. W. W. Colby, D. J. Capon. D. V. GoEdDEL \& A. D. LEvinson: Biological properties 
of human c-Ha-rasl genes mutated at codon 12 . Nature 312, $71-75$ (1984)

20. Valls, L. A., C. P. Hunter, J. H. Rothman \& T. H. STEVENS: Protein sorting in yeast: the localization determinant of yeast vacuolar carboxypeptidase $Y$ resides in the propeptide. Cell 48, 887-897 (1987)

21. Weber, K., J. R. Pringle \& M. Osborn: Measurement of molecular weights by electrophoresis on SDS-acrylamidegel. Methods Enzymol. C. XXVI, 3-27 (1972)

22. Wells. J. A., M. Vasser \& D. B. Powers: Cassette mutagenesis: an efficient method for generation of multiple mutations at defined sites. Gene 34, 315-323 (1985)

23. Winther, J. R., M. C. Kielland-Brandt \& K. BREDDAM: Increased hydrophobicity of the $S_{1}^{\prime}$ binding site of carboxypeptidase $Y$ obtained by site-directed mutagenesis. Carlsberg Res. Commun. 50, 273-284 (1985)

24. Zoller. M. \& M. SMITH: Oligonucleotide-directed mutagenesis of DNA fragments cloned into M13 vectors. Methods Enzymol. 100, 468-500 (1983)

Accepted by H. KLENOw 